\title{
ARTIGO
}

\section{Estudo de Caso: \\ Mesotelioma de Pleura em mecânico-soldador}

Case Study: Pleura mesothelioma in mechanical welder

Estudio de caso: Mesotelioma de Pleura en mecánico-soldador

\section{Mário Parreiras de Faria' Francisco Teixeira da Costa ${ }^{2}$}

RESUMO: O presente artigo trata de estudo de caso de mesotelioma maligno de pleura em trabalhador mecânico-soldador. $\mathrm{O}$ objetivo foi descrever a investigação realizada pela auditoria-fiscal do trabalho a partir de denúncia formulada pelo sindicato dos trabalhadores da categoria profissional a partir do atendimento do trabalhador já aposentado e que recebeu o diagnóstico de mesotelioma de pleura. A metodologia utilizada consistiu em vistoria no local de trabalho, onde o trabalhador exerceu suas atividades por 24 anos, entrevista com o gerente de operação e com o mecânico de operação ainda em atividade no estabelecimento. Buscaram-se dados no Serviço de Segurança e Saúde da empresa, verificando dados do Programa de

\footnotetext{
${ }^{1}$ Mestre em Saúde Pública (UFMG); Auditor-Fiscal do Trabalho; Médico do Trabalho; Ministério do Trabalho, Minas Gerais; E-mail: marioparreiras55@gmail.com

2 Auditor-Fiscal do Trabalho; Engenheiro de Segurança do Trabalho; Ministério do Trabalho, Minas Gerais. 
Prevenção de Riscos Ambientais e do Programa de Controle Médico de Saúde Ocupacional e dos exames de controle de saúde dos trabalhadores realizado pelo Serviço. Foram analisados os resultados de exames complementares a que foi submetido o trabalhador. Evidenciou-se que o mesotelioma maligno de pleura foi causado pela exposição a fibras de amianto durante suas atividades. Conclui-se que em virtude da exposição ao amianto em várias outras atividades que não as tradicionalmente conhecidas de exposição inviabiliza o chamado "uso controlado" desta fibra cancerígena, chamando atenção para que os serviços de atendimento à saúde pública estejam preparados para diagnosticar e estabelecer condutas de manejo dos trabalhadores expostos em décadas passadas.

Palavras-Chave: mesotelioma; inspeção do trabalho; exposição a amianto.

ABSTRACT: This paper is a case study of malignant pleural mesothelioma in a mechanical welder. The objective was to describe the investigation carried out by two labor inspectors due to a complaint made by the union of the workers of the professional category claiming that one retired worker had received pleural mesothelioma diagnosis. The methodology used consisted of a survey in the workplace, where the employee worked for 24 years, interview with the operation manager and with an operation mechanic still active in the establishment. Data was obtained from the company's Health and Safety Service, from the Environmental Risk Prevention Program and the Occupational Health Medical Control Program and from the health checks carried out by the Service. The results of the complementary laboratorial exams to which the worker was submitted were analyzed. It was shown that the pleura malignant mesothelioma was caused by exposure to asbestos fibers during his activities. It is concluded that, due to the exposure to asbestos in several activities other than those traditionally known as hazard, the so-called "controlled 
use" of this carcinogenic fiber is unfeasible and draws attention to the fact that public health services are prepared to diagnose and to address conduits to workers exposed in the past decades.

Keywords: mesothelioma; labor inspection; asbestos.

\section{INTRODUÇÃO}

A associação entre a exposição a todas as formas comerciais de fibras de asbestos (amianto) e câncer de pulmão e mesotelioma tem sido estabelecida em vários estudos epidemiológicos, sendo considerada comprovadamente cancerígena conforme a International Agency for Research on Cancer (Iarc, 2012), que concluiu que há evidências suficientes de que todas as formas de asbestos (incluindo a crisotila, crocidolita, amosita, tremolita e actinolita) são carcinogênicas, com um aparente menor risco para o amianto crisotila. Marsili et al. (2016) concluem que mais de quarenta anos de pesquisas tem consistentemente confirmado a carcinogenicidade do amianto em todas as suas formas. Segundo a literatura (Wünsch Filho e Koifman, 2003, Prado, Cazian e Caruso, 2014), o mesotelioma maligno de pleura é uma doença rara, extremamente agressiva com uma sobrevida menor que um ano após o diagnóstico, embora haja indicações de crescimento de sua ocorrência no Brasil, entre aqueles que tiveram exposição ocupacional ou ambiental ao amianto, que é causa específica desta doença. Por seu turno, Algranti e Capitani (2014) estimam que menos de $10 \%$ dos expostos se encontrariam em atividades dentro da indústria considerada típica de exposição, limitando o controle da exposição apenas àquele número pequeno de expostos. Segundo o Ministério da Saúde (Brasil, 2001), a relação etiológica dos mesoteliomas malignos com o amianto foi estabelecida por Wagner e colaboradores 
em trabalho publicado em 1960 (Wagner, Sleggs e Marchand, 1960). Ainda segundo o Ministério da Saúde (Brasil, 2001, p. 120) é de cerca de $90 \%$ a probabilidade de que adultos que desenvolvem mesotelioma maligno de pleura ou peritônio tenham trabalhado expostos ao amianto, sendo que todos os tipos de fibra são carcinogênicos para a gênese dessas patologias malignas. Tais fibras são consideradas já que atuam como iniciadores e promotores do processo cancerígeno. Segundo a referida publicação, "o desenvolvimento desses tumores malignos não parece ser dosedependente, o que significa que, em princípio, qualquer número de fibras pode iniciar ou promover o tumor" (Brasil, 2001, p. 120). Cabe destacar que o período de latência, entre a primeira exposição e a manifestação do mesotelioma maligno é longo, podendo ser de 35 a 40 anos, ainda que alguns trabalhos mostrem períodos relativamente curtos, em torno de 20 anos, porém, raramente inferior a 15 anos (Brasil, 2001, p. 120 e Prado, Cazian e Caruso, 2014 ).

\section{OBJETIVO}

Este estudo tem por objetivo descrever a investigação realizada pela auditoria-fiscal do trabalho de caso de mesotelioma maligno de pleura em trabalhador que exerceu atividade de soldador industrial em usina termelétrica por 24 anos, tendo apresentado diagnóstico de sua doença após sua aposentadoria e falecido seis meses após seu diagnóstico.

\section{METODOLOGIA}

O Sindicato dos Trabalhadores, representante da categoria profissional, apresentou denúncia ao órgão regional do Ministério do Trabalho em Minas Gerais, dando conta de que o trabalhador ao ser atendido no ambulatório médico do Sindicato teve diagnóstico de mesotelioma de pleura confirmado por exames complementares e baseado na história ocupacional emitiu a Comunicação de Acidente de Trabalho.

Laborare. Ano I, Número 1, Julho/2018, pp. 119-128. ISSN 0000-0000. http://trabalhodigno.org/laborare 
Segundo informações fornecidas pelo Sindicato, o trabalhador apresentou lesões pleurais após aposentadoria, sendo que em 02/02/2009, após biópsia pleural, os exames imunohistóquímicos evidenciaram o diagnóstico de mesotelioma maligno de pleura, vindo a falecer da doença em 06/08/2009.

Recebida a denúncia, os auditores-fiscais do trabalho, autores deste estudo, compareceram à empresa com o objetivo de verificar a possibilidade de manutenção da exposição de outros trabalhadores à exposição a fibras de amianto, tomando informações dos trabalhadores em atividades de solda na empresa e do engenheiro de operações do estabelecimento na busca de evidências de possível exposição a fibras de amianto. Além disso, compareceram ao serviço de segurança e medicina do trabalho da sede da empresa, quando se solicitaram cópias do Programa de Prevenção de Riscos Ambientais (PPRA) e do Programa de Controle Médico de Saúde Ocupacional (PCMSO) do estabelecimento em que o trabalhador exercia suas atividades, além dos exames médicos dos trabalhadores.

\section{RESULTADOS}

\section{a) O trabalhador:}

E.C.A, casado, nascido em 26/02/1952, masculino, com escolaridade de ensino médio completo. Havia trabalhado na obra de construção da usina termelétrica em 1978 e foi admitido na empresa como mecânico de manutenção (soldador) em 01/03/1980 vindo a se aposentar em 2004, 24 anos depois da admissão. Fez os exames médicos admissionais e periódicos conforme a legislação, mas não foi submetido a exames específicos para exposição a amianto. 
Por ocasião do atendimento do trabalhador pelo Sindicato dos Trabalhadores foram realizados os seguintes exames:

1. Tomografia computadorizada de tórax, datada de 18/06/2008, que mostrou, entre outros achados, "placas pleurais à esquerda, sem derrame pleural associado, podendo corresponder a doença pleural associada ao asbesto".

2. Ressonância Magnética de Tórax, datada de 10/01/2009, com a seguinte conclusão: "lesões predominantemente pleurais, algumas delas infiltrando o espaço intercostal e com extensão para a parede torácica paravertebral médio-inferior esquerda, com características expansivas. Considerar a possibilidade de mesoteliomas associados ao quadro de suposta asbestose".

3. Exame de imunohistoquímica de biópsia pleural datado de 10/02/2009, revelou que "os achados histológicos e imunohistoquímicos favorecem o diagnóstico de um mesotelioma da variante linfo-histiocitóide.” [...]. “O diagnóstico diferencial com carcinoma sarcomatóide pulmonar ou de outros locais é muito difícil, mas a positividade para calretinina aponta para mesotelioma.”.

\section{b) O local de trabalho:}

O local de trabalho é uma Usina Termoelétrica a óleo derivada de petróleo, que teve sua instalação iniciada no ano de 1978, funcionando intermitentemente desde então, conforme demanda do Operador Nacional do Sistema Elétrico. No momento da vistoria, a Usina encontrava-se fora de 
operação. Na Usina se encontrava instalada uma turbina de grande capacidade para geração de energia elétrica, movida a vapor proveniente de caldeira de grande porte (400 toneladas/hora).

\section{c) Entrevistas:}

O Engenheiro de Operações relatou que trabalhava na empresa há mais de 20 anos, sendo que era responsável pela operação da Usina. Informou que eram utilizadas mantas de amianto durante as manutenções corretivas e preventivas, eram também realizadas operações de solda nas tubulações da caldeira. As mantas de amianto eram utilizadas para cobrir as soldas, logo após a sua execução, para um resfriamento lento da solda, denominado alívio térmico. Relatou que a partir de 2002, determinou a eliminação das mantas de amianto, pois teve notícias na imprensa do risco do amianto para a saúde dos operadores, que foram substituídas por lã de rocha e fibras cerâmicas refratárias.

Um dos mecânicos de manutenção, também entrevistado, confirmou a informação do Engenheiro de Operação. Relatou que durante a manipulação das mantas de amianto era comum o desprendimento de fibras das mantas o que também ocorria durante a retirada de restos das mantas das tubulações já soldadas. Disse que as operações de solda não eram constantes e que durante as referidas operações os mecânicos/soldadores não utilizavam máscaras respiratórias de filtros específicas, mas apenas os protetores faciais para solda. Relatou que não fazia RX de tórax ou espirometria, mas que, a partir de setembro de 2009, os mecânicos de manutenção foram convocados para serem submetidos aos referidos exames. 
Durante a auditoria, verificou-se pelas análises dos Programas de Prevenção de Riscos Ambientais (PPRA), de 1998 e 2002, que o risco de exposição a fibras de amianto/asbesto não era avaliado ou mesmo indicado nos documentos-base. Os PPRA dos anos de 2000 e 2001 não foram apresentados, pois, segundo informações, não foram localizados. A análise do Programa de Controle Médico de Saúde Ocupacional (PCMSO) não apontava o risco de inalação de fibras de amianto/asbesto pelos mecânicos soldadores, que assim, não eram submetidos ao controle médico da exposição (RX de tórax e espirometria).

O Serviço de Medicina do Trabalho da empresa informou que a partir de setembro de 2009, após tomar ciência da morte do trabalhador por meio de contato do Sindicato dos Trabalhadores, passou a realizar exames de RX de tórax e espirometria, nos trabalhadores ainda em atividade e convocou os trabalhadores aposentados por meio de telegrama para fazer os mesmos exames. Até a data da ação fiscal haviam sido examinados 23 trabalhadores (oito ativos e quinze aposentados). Onze trabalhadores aposentados foram convocados, mas não compareceram ao exame. Dos quinze trabalhadores aposentados que compareceram ao exame e foram submetidos a RX de tórax, treze exames foram considerados normais por dois leituristas e dois exames realizados em 11/09/09 e 29/09/09 apresentaram alterações nas radiografias de tórax: um trabalhador apresentou pequenas nodulações densas e estrias marginais em periferia pulmonar esquerda e outro apresentou estrias fibróticas na base esquerda. Ambos os trabalhadores estavam aguardando serem submetidos à Tomografia Computadorizada de Alta Resolução para esclarecimento diagnóstico. 


\section{CONCLUSÃO}

Considerando a literatura citada e os dados obtidos durante esta investigação, podemos concluir que o mesotelioma de pleura que vitimou o trabalhador guarda relação direta de nexo causal com sua atividade desenvolvida durante sua vida laboral como mecânico/soldador, desde 1978, quando foi contratado para a obra de montagem da Usina, permanecendo na atividade até sua aposentadoria em 2004.

Ressalta-se a ineficácia do PCMSO implementado pela empresa que se baseou apenas nas informações contidas no PPRA que, como visto, foi omisso na identificação do risco de exposição dos trabalhadores a fibras de amianto durante suas atividades. Enfatiza-se, assim, a necessidade de os profissionais de segurança e saúde das empresas realizarem uma avaliação completa dos ambientes de trabalho e conhecer todo o processo de trabalho e a organização das atividades dos trabalhadores, especialmente em patologias com período de latência prolongada como o caso analisado. Esse caso chama atenção para a necessidade de todos os profissionais de saúde atentarem para a exposição pregressa de trabalhadores em atividades não consideradas clássicas da exposição a fibras de amianto como mineração, fabricação de produtos de fibrocimento ou de material de fricção. Ressalta a importância de se colher uma boa história ocupacional além de verificar os locais de trabalho e as atividades dos trabalhadores de forma a permitir uma avaliação correta da exposição e a realização de exames de controle da saúde dos trabalhadores específicos para exposição ao amianto. Os profissionais de saúde e a auditoria-fiscal do trabalho devem sempre avaliar as condições de possível exposição ao agente cancerígeno nas atividades de manutenção muitas vezes negligenciadas, como mostrado no presente estudo de caso.

Conclui-se que, em virtude da exposição ao amianto, em várias outras atividades que não as tradicionalmente conhecidas de exposição, inviabiliza-se o chamado "uso 
controlado" dessa fibra cancerígena e chama atenção para que os serviços de atendimento à saúde pública estejam preparados para diagnosticar e estabelecer condutas de manejo do trabalhadores, visto que os expostos em décadas passadas poderão se apresentar adoecidos nos próximos anos.

\section{REFERÊNCIAS BIBLIOGRÁFICAS}

Algranti, E.; De Capitani, EM. (2014). In: Santos, UP (Org.). Pneumologia ocupacional ilustrada: fotos e fatos. 1. ed. São Paulo: Atheneu. p. 91- 96.

Brasil. Ministério da Saúde do Brasil (2001). Doenças relacionadas ao trabalho: manual de procedimentos par os serviços de saúde. Elizabeth Costa Dias (Org.). Colaboradores Idelberto Muniz de Almeida e al. Brasília: Ministério da Saúde do Brasil.

IARC - International Agency for Research on Cancer. (2012). Arsenic, metals, fibres, and dusts volume $100 \mathrm{C}$ A review of human carcinogen. Lyon, France. Disponível em: http://monographs.iarc.fr/ENG/Monographs/vol100C/mono100C.pdf Acesso em: 06 mar. 2018.

Marsili, D. et al. (2016). Prevention of Asbestos-Related Disease in Countries Currently Using Asbestos. Int. J. Environ. Res. Public Health. Vol. 13. p. 494; doi:10.3390/ijerph13050494.

Prado, GF., Cazian, M., Caruso, RC. (2014). Câncer de Pulmão e Mesotelioma Maligno de Pleura. In: Santos, UP (Org.). Pneumologia ocupacional ilustrada: fotos e fatos. 1. ed. São Paulo: Atheneu. p. 131-139.

Wagner, JC. , Sleggs, CA, Marchand, P. (1960). Diffuse pleural mesothelioma and asbestos exposure in North Western Cape Province. Brit J Ind Med. Vol. 17, N. 4. Out. $\quad$ pp. 260-71. Disponível em: https://www.ncbi.nlm.nih.gov/pmc/articles/PMC1038078/ Acesso em: 04 mar 2018

Wünsch Filho, V.; Koifman, S. Tumores Malignos Relacionados com o Trabalho (2003). In: Mendes, R. Patologia do Trabalho. 2. ed. atual. ampl. Vol. 2. São Paulo: Atheneu. 